\title{
Quality of life in postoperative Japanese hip fracture patients: a hospital-based prospective study
}

\author{
Nobuki Sugeno $\cdot$ Aya Goto $\cdot$ Seiji Yasumura $\cdot$ \\ Shin-ichi Kikuchi
}

Received: 24 January 2008 / Accepted: 9 July 2008 / Published online: 7 October 2008

(C) The Author(s) 2008. This article is published with open access at Springerlink.com

\begin{abstract}
Summary This study aimed to study quality of life (QOL) in postoperative Japanese hip fracture patients. Although QOL in Japanese patients recovered to pre-fracture levels 1 year following hospitalization, the recovery varied and was associated with physical factors and living arrangements. Introduction The aim of this study was to investigate qualityof-life (QOL) changes in postoperative Japanese hip fracture patients.

Methods Subjects were 113 hip fracture patients recruited and followed for 1 year following hospitalization. QOL was assessed using the Euro-QOL, which consists of the health status part (EQ-5D) and the visual analogue scale (EQ-VAS). Factors associated with change in QOL (calculated by subtracting pre-fracture score from the score at 1 year following hospitalization) were determined by multiple linear regression analysis.

Results Of 81 patients who did not exhibit severe cognitive decline, 50 completed the follow-up surveys and were included for analysis. The mean difference from baseline was 0.035 (standard deviation $=0.254$ ) for EQ-5D, and 17.0 (22.0) for EQ-VAS. Age, fracture type and residence status were significantly associated with a change in EQ-5D
\end{abstract}

\footnotetext{
N. Sugeno $(\bowtie) \cdot$ S.-i. Kikuchi

Department of Orthopaedic Surgery,

Fukushima Medical University School of Medicine,

Hikariga-oka 1,

Fukushima City 960-1295, Japan

e-mail: suge-pu-@par.odn.ne.jp

N. Sugeno $\cdot$ A. Goto $\cdot$ S. Yasumura

Department of Public Health,

Fukushima Medical University School of Medicine,

Fukushima City, Japan
}

score. Cognitive function, activities of daily living and household help were significantly associated with a change in EQ-VAS score.

Conclusions Contrary to previous studies from western countries, we found that QOL in Japanese patients recovered to pre-facture levels 1 year following hospitalization. This change varied between patients, and was associated with both physical factors and living arrangements.

Keywords Postoperative quality of life -

Postoperative outcomes $\cdot$ Hip fracture $\cdot$ Japan

\section{Introduction}

One of the major consequences of osteoporosis is hip fracture. This is a common and potentially devastating injury in the elderly [1]. While the incidence of hip fracture in Asian countries (including Japan) is lower than that reported in Northern Europe and North America, concerning increases in occurrence rates have been noted in recent years [2]. A multi-country study in 1999 reported that the ageadjusted annual incidence of hip fracture per 100,000 people was 54 for males and 155 for females in Japan (Tottori Prefecture), 52 for males and 136 for females in China (Hong Kong), 147 for males and 335 for females in the United States (Rochester, Minnesota), and 173 for males and 405 for females in Sweden (Malmö) [3]. Hip fracture incidence in Japan has been increasing annually [4], and it is has been estimated that the number of cases will more than double between 1994 and 2025 [5]. Similarly, the hip fracture rate increased fivefold in Singapore between 1960 and 1990 [6] and fourfold in South Korea between 1991 and 2001 [7]. In 1990, 26\% of worldwide hip fractures occurred 
in Asia. This figure is expected to rise to $37 \%$ by 2025 and to $45 \%$ by 2050 [5].

Treatments for hip fracture aim to prevent the progression of disability and to restore pre-fracture function $[8,9]$. These can be more efficiently achieved by early operation and rehabilitation $[10,11]$. Most femoral neck fractures are treated with hemi-arthroplasty, while trochanteric fractures are treated with internal fixation. In Japan, more than $90 \%$ of hip fracture patients are treated surgically [5]. Mean waiting time between hospitalization and operation is reported to be 11 days, while the average time between operation and discharge is 50 days. Both of these waiting times are longer than those reported in Europe and North America [12]. Fortunately, the number of cases successfully receiving an operation within two days following injury has been increasing in Japan [13].

Although advances in orthopedic treatment have led to improvements in the treatment of hip fractures [14], recovery is still slower than expected and rehabilitation is often incomplete [13,14]. A study of 10,992 Japanese hip fracture patients revealed that $51 \%$ of these patients were able to partake in normal activities of daily living (ADL) before the fracture, but that this percentage decreased by $24 \%$ after the fracture [12]. The 1-year post-operative mortality rate in this population was approximately $10 \%$ [12]. A number of studies have focused on walking ability and ADL recovery after hip fracture and noted that age, sex, walking ability before injury, fracture type, complication before fracture, and cognitive function are important prognostic factors $[11,13]$. The influence of cognitive function in this regard remains controversial $[15,16]$.

In addition to the traditional physical outcome evaluation after hip fracture, assessment of quality of life (QOL) is becoming increasingly used. Studies in western countries have revealed that QOL does not return to pre-fracture levels following hip fracture. Other studies have examined various clinical factors influencing QOL, and the differences between patients and community dwellers [17-23]. To date, epidemiological investigation of these issues in Asian populations has been scarce [24].

The primary aims of this study were to investigate the change in QOL after hip fracture in Japanese patients and to determine the factors associated with these changes. There are numerous QOL assessment tools, but most are lengthy and difficult to apply in daily clinical practice or are not relevant for elderly patients. We thus selected the EuroQOL questionnaire [25-27], which is short and easy to complete [28] and has been used previously for assessing QOL associated with various diseases including hip fracture $[29,30]$. This questionnaire has also been demonstrated to correlate well with scores obtained using Short Form 36 [31] and the Nottingham Health Profile [32] among hip fracture patients.

\section{Materials and methods}

Study design and subjects

We conducted a hospital-based prospective study of hip fracture patients admitted to Ohara General Hospital (Fukushima City, Fukushima Prefecture, Japan) between December 2004 and November 2005. Patients were assessed 1 or 2 days after admission (preoperation), just prior to discharge and 3, 6, and 12 months after the day of admission.

Assessment tools

Questionnaires conducted during hospitalization assessed the following: age, sex, residence type prior to hospitalization and following discharge, fracture type, operation type, waiting time between hospitalization and operation, length of hospital stay, cognitive function, number of comorbidities, and ADL and QOL prior to fracture. In surveys after discharge, residence type, the presence of household help, ADL and QOL were assessed.

Quality-of-life was assessed using the Euro-QOL [2527], which consists of two sections: the health status part (EQ-5D) and the visual analogue scale (EQ-VAS). The EQ$5 \mathrm{D}$ includes five questions regarding mobility, self-care, daily activities, pain/discomfort, and anxiety/depression. Each item is divided into three degrees of severity: no problem, some problem and major problem. By applying scores from EQ-5D "value sets" elicited from general Japanese population samples, health states defined by the five-dimensional descriptive system are converted into a weighted health state index. In this index, 1.000 is indicative of 'full' or 'good health' and 0.000 is indicative of death. EQ-VAS is a $20-\mathrm{cm}$ visual analogue scale on which a respondent is asked to mark his or her state of health on a thermometer-like line ranging from 0 to 100 .

Activities of daily living was evaluated using the Barthel index score [33], which assesses the ability of an individual to care for him/herself. The index includes the following ten items: feeding, transfers, personal grooming and hygiene, bathing, using the toilet, walking, ascending and descending stairs, and bowel and bladder control. Each item is scored between 0 (completely dependent) and 10 or 15 (independent), with the total score ranging from 0 to 100 . Higher scores denote greater independence in performing ADL.

Baseline assessments of ADL and QOL at the time of admission determined pre-hip fracture status for these measures. Since it is difficult to prospectively collect information prior to injury, pre-injury recall is often used as an alternative method of assessment in QOL studies of fracture patients $[8,9,14,16-22]$. It should be noted that the accuracy of this assessment in describing pre-fracture status is debatable [20]. 
Cognitive function was measured using the mini-mental state examination (MMSE), which consists of 13 items [34]. Each item is scored as 0 (incorrect answer/impossible to answer) or one (correct answer), and the total score ranges from 0 to 30 . We classified our patients into three cognitive groups with respect to MMSE score: severe cognitive decline (a score less than 15), moderate cognitive decline (a score between 15 and 23) and normal (a score over 23). Cognitive function was assessed twice at admission and just prior to discharge, with the higher score being retained for purposes of analysis [15].

Interviews regarding ADL and QOL were conducted by nursing staff, physical therapists, and doctors (including the first author).

\section{Statistical analysis}

The statistical package used for analysis was SPSS for Windows, version 14.0 (SPSS Japan Inc., Tokyo, Japan). As in many previous studies [10, 18, 22-24, 30-32], patients exhibiting severe cognitive decline were excluded from this study due to difficulties in answering QOL questions. Chi-square tests and Student's $t$ tests were used to compare categorical and continuous characteristics of patients, respectively. Changes in ADL and QOL levels before fracture, at discharge and 1 year following hospitalization were compared using one-way repeated measures analysis of variance with Bonferroni adjustment.

Multiple linear regression analysis was performed to determine the factors associated with the change in QOL, which was calculated by subtracting the pre-injury EQ-5D or EQ-VAS from the score 1 year following hospitalization. The following 10 variables were included in the analysis: age (year), sex (1=male, $2=$ female), fracture type $(1=$ femoral neck fracture, $2=$ trochanteric fracture), operation type $(1=$ hemi-arthroplasty, $2=$ compression hip screw or gamma nail, $3=$ multiple pinning), length of hospital stay (days), cognitive function ( $1=$ normal, $2=$ moderate cognitive decline), number of comorbidities, type of residence 1 year following hospitalization ( $1=$ own home, $2=$ other), household help required 1 year following hospitalization $(1=\mathrm{yes}, 2=\mathrm{no})$ and change in Barthel index (score one year following hospitalization minus the baseline score). Operation type was graded according to invasiveness. For the analysis of change in EQ-5D, the change in Barthel index score was excluded as an independent variable because ADL questions were included in the EQ-5D.

\section{Ethical considerations}

All patients with normal cognitive function provided informed consent; for patients with cognitive dysfunction and other disorders, a family member provided the consent. The study was approved by the ethical committees of Fukushima Medical University and Ohara General Hospital.

\section{Results}

One hundred and thirteen patients were recruited and registered for the study (Table 1). The mean age was 80.5 years, and $79 \%$ of patients were female. Half had femoral neck fractures and the other half had trochanteric fractures. Only 11 patients (10\%) exhibited no comorbidities. Eighty-eight patients (78\%) were admitted from their own home. Mean waiting time between hospitalization and operation was 2.0 days. Mean length of hospital stay was 31 days. Forty-nine patients $(43 \%)$ were transferred to a long-term care hospital, while 39 (35\%) returned home.

Thirty-one patients (27\%) exhibited severe cognitive decline and were excluded from analyses (Fig. 1). In addition, we were not able to evaluate the cognitive function of one patient due to an articulation disorder and a hearing impairment. Thus, of the total patients surveyed, $81(72 \%)$ were eligible for evaluation. Fifty of these patients completed the 1-year follow-up (62\%). Of the 31 patients who did not complete the follow-up, eight were deceased, ten could not be contacted, and two moved to other prefectures. Complete QOL data could not be obtained for the remaining 11 patients who were followed up. Of these 11 patients, eight failed to come for follow-up visits and were contacted by telephone. When characteristics between patients who were and were not entered into the final analyses were compared, significant differences were found for fracture type $(p<0.01)$, operation type $(p<0.01)$ and cognitive function $(p=0.01)$, but not for age $(p=0.24)$ (Table 1).

As shown in Figs. 2, 3, and 4 mean Barthel index and EQ-5D scores decreased between the pre-fracture assessment time and discharge, while EQ-VAS scores remained unchanged. After discharge, scores for all three indicators increased. Table 2 shows the change in score for each variable between the pre-fracture assessment point (baseline) and the point 1 year following hospitalization. The mean difference was -0.8 (standard deviation $[\mathrm{SD}]=11.7]$ ) for the Barthel index, $0.035(\mathrm{SD}=0.254)$ for $\mathrm{EQ}-5 \mathrm{D}$ and $17.0(\mathrm{SD}=22.0)$ for EQ-VAS.

The outcomes of the multiple linear regression analyses examining factors associated with the changes in EQ-5D and EQ-VAS are presented in Tables 3 and 4.. Age $(B=$ $0.01)$, fracture type $(B=-0.21)$ and residence type 1 year following hospitalization $(B=-0.25)$ were significantly associated with changes in EQ-5D score. The adjusted 
Table 1 Characteristics of the study population

\begin{tabular}{|c|c|c|c|c|}
\hline & \multicolumn{3}{|c|}{$N(\%)$ or Mean $(S D)$} & \multirow[b]{2}{*}{$p$ value ${ }^{\text {a) }}$} \\
\hline & $\begin{array}{l}\text { Registered } \\
(n=113)\end{array}$ & $\begin{array}{l}\text { Analyzed } \\
(n=50)\end{array}$ & $\begin{array}{l}\text { Not analyzed } \\
(n=31)\end{array}$ & \\
\hline Age (year) & $80.5(9.7)$ & $77.4(10.2)$ & $80.1(9.1)$ & 0.24 \\
\hline \multicolumn{5}{|l|}{ Sex } \\
\hline Male & $24(21.2)$ & $10(20.0)$ & $7(22.6)$ & \multirow[t]{2}{*}{0.79} \\
\hline Female & $89(78.8)$ & $40(80.0)$ & $24(77.4)$ & \\
\hline \multicolumn{5}{|l|}{ Residence type prior to hospitalization } \\
\hline Home & $88(77.9)$ & $44(88.0)$ & $27(87.1)$ & \multirow[t]{3}{*}{0.43} \\
\hline Nursing home & $14(12.4)$ & $2(4.0)$ & $0(0.0)$ & \\
\hline Other hospital & $11(9.7)$ & $4(8.0)$ & $4(12.9)$ & \\
\hline \multicolumn{5}{|l|}{ Fracture type } \\
\hline Femoral neck & $57(50.4)$ & $35(70.0)$ & $9(29.0)$ & \multirow[t]{2}{*}{$p<0.01$} \\
\hline Trochanteric & $56(49.6)$ & $15(30.0)$ & $22(71.0)$ & \\
\hline \multicolumn{5}{|l|}{ Operation type } \\
\hline Hemiarthroplasty & $40(35.4)$ & $27(54.0)$ & $6(19.4)$ & \multirow[t]{4}{*}{$p<0.01$} \\
\hline Compression hip screw or gamma nail & $57(50.4)$ & $17(34.0)$ & $21(67.7)$ & \\
\hline Multiple pinning & $13(11.5)$ & $6(12.0)$ & $2(6.5)$ & \\
\hline No operation & $3(2.7)$ & $0(0.0)$ & $2(6.5)$ & \\
\hline Waiting time between hospitalization and the operation (day) & $2.0(1.4)$ & $1.9(1.4)$ & $2.3(1.6)$ & 0.27 \\
\hline Length of hospital stay (day) & $31.1(17.5)$ & $32.3(7.2)$ & $34.8(29.2)$ & 0.64 \\
\hline \multicolumn{5}{|l|}{ Residence type after discharge } \\
\hline Own home & $39(34.5)$ & $27(54.0)$ & $8(25.8)$ & \multirow[t]{5}{*}{0.05} \\
\hline Family's house & $2(1.8)$ & $1(2.0)$ & $1(3.2)$ & \\
\hline Long-term care type hospital & $49(43.3)$ & $16(32.0)$ & $19(61.3)$ & \\
\hline Nursing home & $19(16.8)$ & $6(12.0)$ & $2(6.5)$ & \\
\hline Death & $5(3.5)$ & - & $1(3.2)$ & \\
\hline \multicolumn{5}{|l|}{ Cognitive function (Mini-Mental State Examination) } \\
\hline Normal (24 or higher) & $45(39.8)$ & $34(68.0)$ & $11(35.5)$ & \multirow[t]{4}{*}{0.01} \\
\hline Moderate cognitive decline (15-23) & $36(31.9)$ & $16(32.0)$ & $20(64.5)$ & \\
\hline Severe cognitive decline (less than 15 ) & $31(27.4)$ & - & - & \\
\hline Not-measured & $1(0.9)$ & - & - & \\
\hline \multicolumn{5}{|l|}{ Number of comorbidities } \\
\hline 0 & $11(9.7)$ & $6(12.0)$ & $2(6.5)$ & \multirow[t]{5}{*}{0.38} \\
\hline 1 & $24(21.2)$ & $11(22.0)$ & $3(9.7)$ & \\
\hline 2 & $36(31.9)$ & $16(32.0)$ & $10(32.3)$ & \\
\hline 3 & $29(25.7)$ & $14(28.0)$ & $10(32.3)$ & \\
\hline $4-6$ & $13(11.5)$ & $3(6.0)$ & $5(16.1)$ & \\
\hline \multicolumn{5}{|l|}{ Residence type one year following hospitalization } \\
\hline Own home & - & $44(88.0)$ & - & \multirow[t]{2}{*}{-} \\
\hline Other & - & $6(12.0)$ & - & \\
\hline \multicolumn{5}{|l|}{ Household help required one year following hospitalization } \\
\hline Yes & - & $23(46.0)$ & - & \multirow[t]{2}{*}{-} \\
\hline No & - & $27(54.0)$ & - & \\
\hline
\end{tabular}

Differences in characteristics between patients who were and were not included in the overall analyses were examined. Differences were compared by Chi-square test for categorical variables and Student's $t$ test for continuous variables.

$S D$ standard deviation.

$R$-squared value for this model was 0.16 . Cognitive function $(B=-14.40)$, household help 1 year following hospitalization $(B=19.18)$ and a change in Barthel index $(B=$ 0.73 ) were significantly associated with changes in EQVAS (adjusted $R$-squared value was 0.25 ).

\section{Discussion}

This is the first study reporting QOL changes in postoperative hip fracture patients in Japan. Contrary to the results of previous studies from other countries, we found that 
Fig. 1 Patient registration and follow-up. MMSE mini-mental state examination. a One patient died during hospitalization; the other seven died following discharge

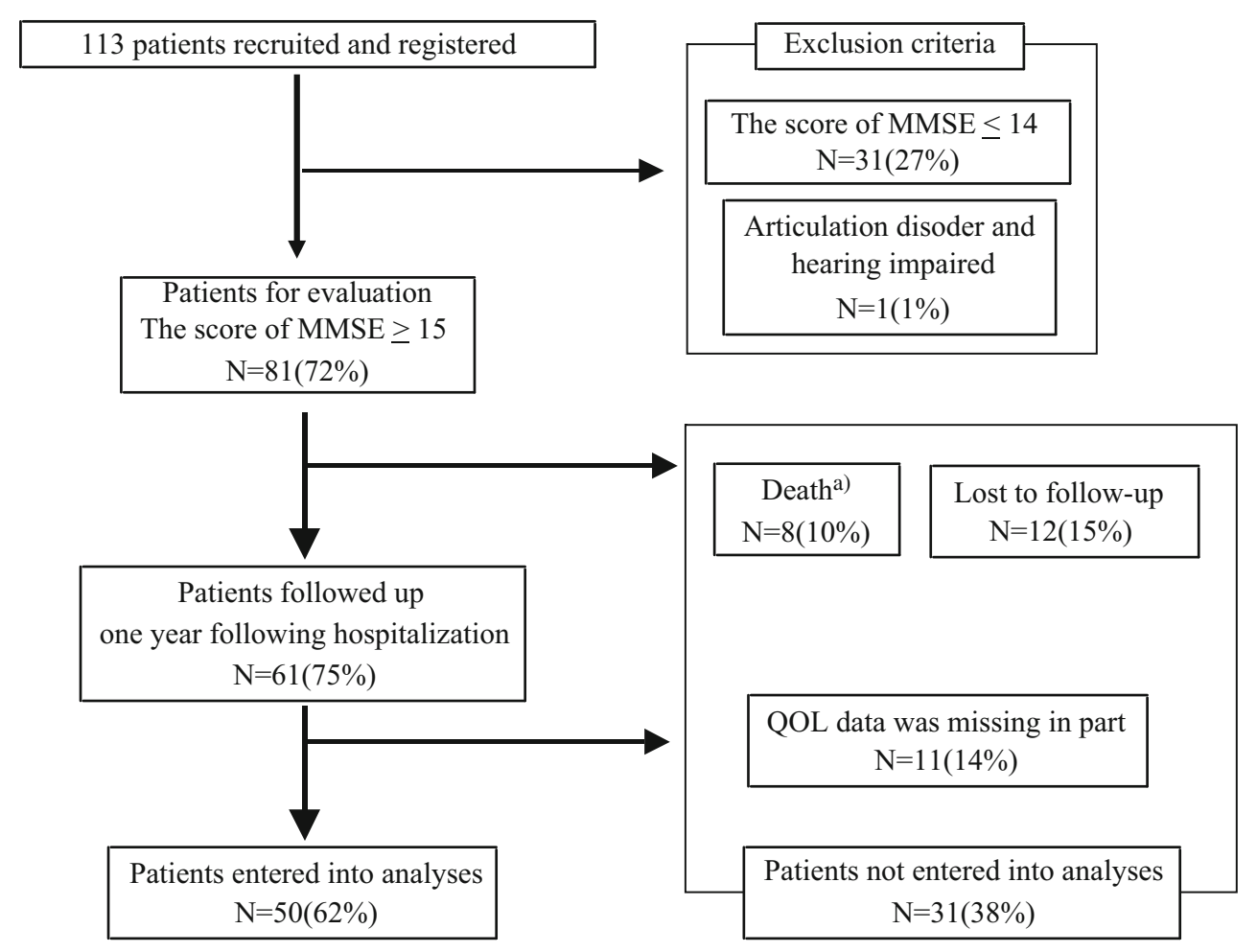

QOL recovered to pre-facture levels 1 year following hospitalization. This discrepancy might be due in part to ethnic differences; however, differences in study design limit such international comparisons with previous studies. One important difference is the criteria for including or excluding subjects as mentioned below. In general, Asians are known to report higher QOL levels compared to Westerners of the same health condition [35]. Further international studies are required to understand how cultural values and norms might result in QOL differences.
An individual's concept of QOL may change over time and in response to changing circumstances. The 'secondary gain' in QOL occurs when patients with impairments adapt to their new conditions [36]. Patients who experience disability can find enriched meaning in their lives after becoming disabled. Similar interpretations for a small change in QOL following physical decline can be explained by the "disability paradox" [36] and "response shift" [37]. These concepts refer to a change in the meaning of one's evaluation of QOL, such that patients might provide

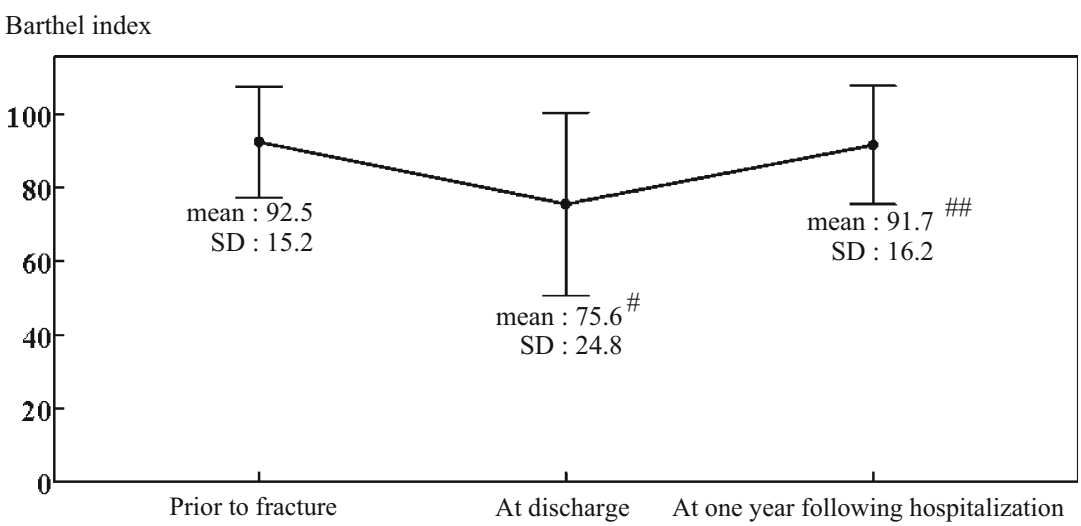

Fig. 2 Barthel index scores in patients prior to hip fracture, at discharge and 1 year following hospitalization. Means and standard deviations of 50 patients who completed follow-up are shown. To compare the scores prior to fracture, at discharge, and 1 year following hospitalization, one-way repeated measures analysis of variance with
Bonferroni adjustment was used. Pound symbol The score at discharge was significantly lower than the score prior to fracture $(p<0.01)$. Two pound symbols The score at 1 year following hospitalization was significantly higher than the score at discharge $(p<0.01)$ 
EQ-5D

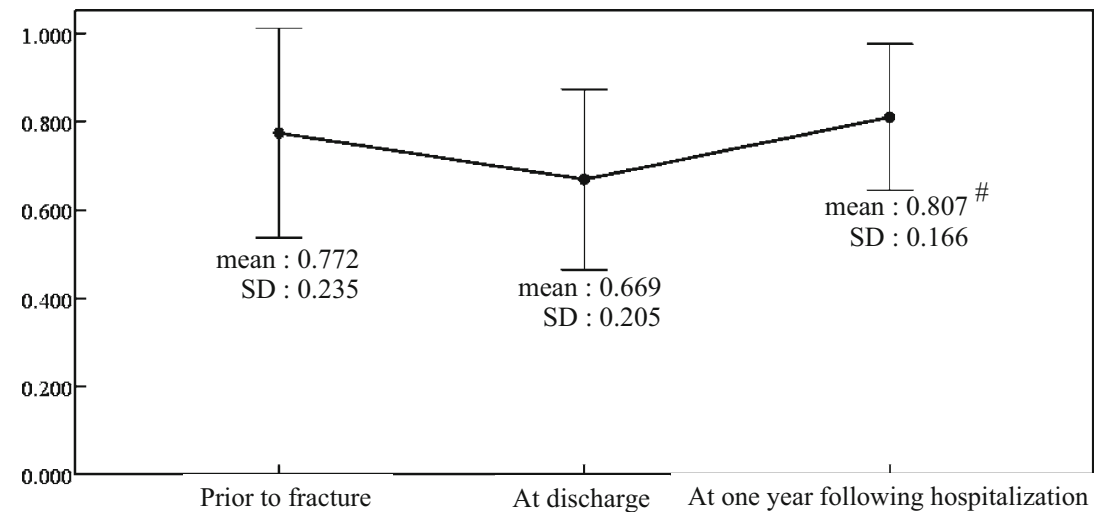

Fig. 3 EQ-5D scores in patients prior to hip fracture, at discharge and 1 year following hospitalization. Means and standard deviations of 50 patients who completed follow-up are shown. To compare the scores prior to fracture, at discharge and 1 year following hospitalization,

different answers to QOL questions over time, not only because their health or QOL has changed, but also because their perception of what health or QOL means may have changed.

Another explanation for the high QOL in our cohort is their favorable postoperative functional recovery. Early functional recovery and independence in daily life are very important to a patient's QOL [10]. Studies examining patients from other countries have reported significant functional decline following hip fracture $[8,9,21]$, whereas we detected only a slight decrease. The favorable recovery of patients in this study compared to some previous studies could be explained, in part, to our exclusion of patients with severe cognitive decline $[9,21]$. However, our patients exhibited better functional outcomes even when compared one-way repeated measures analysis of variance with Bonferroni adjustment was used. Pound symbol The score at 1 year following hospitalization was significantly higher than the score at discharge $(p<0.01)$

with the majority of previous studies that excluded those with cognitive decline [8]. For elderly hip fracture patients, early surgery and promptly initiated post-surgical rehabilitation have been reported to improve functional recovery and prevent postoperative complications [11]. Many of our patients were operated on within 2 days of admission and started rehabilitation the following day. This is earlier than average in Japan and might have contributed to the favorable ADL recovery.

Despite the possible positive shift in one's internal standard of measurement, changes in EQ-5D and EQ-VAS varied quite dramatically. We thus investigated factors associated with the changes in QOL. Our results revealed that older age, femoral neck fracture, and residence at home all exerted a positive influence on change in EQ-5D, while

EQ-VAS

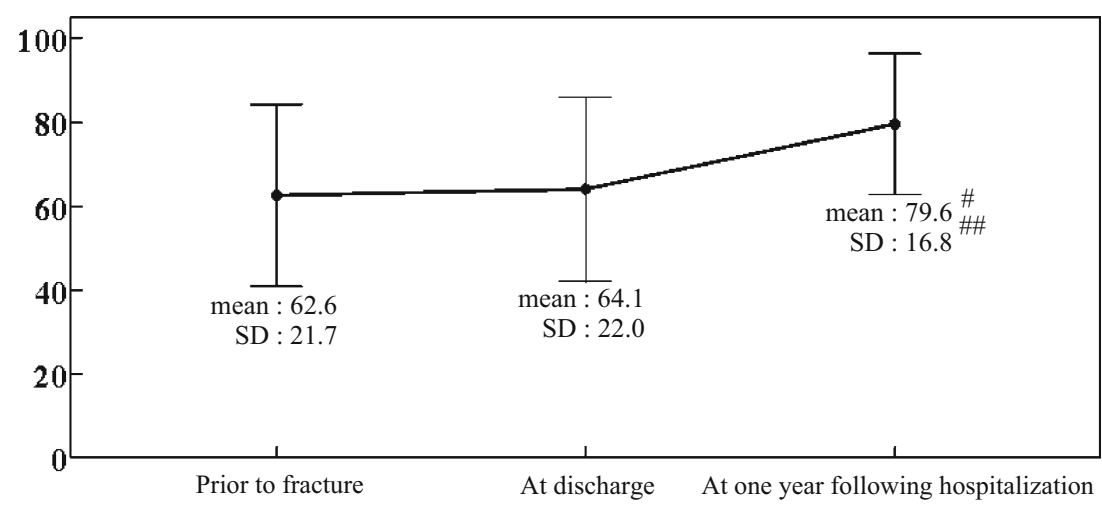

Fig. 4 EQ-VAS scores in patients prior to hip fracture, at discharge and 1 year following hospitalization. Means and standard deviations of 49 patients who completed follow-up are shown. To compare the scores prior to fracture, at discharge, and 1 year following hospitalization, one-way repeated measures analysis of variance with
Bonferroni adjustment was used. Pound symbol The score at 1 year following hospitalization was significantly higher than the score prior to fracture $(p<0.01)$. Two pound symbols The score at 1 year following hospitalization was significantly higher than the score at discharge $(p<0.01)$ 
Table 2 Changes in EQ-5D, EQ-VAS, and Barthel index

\begin{tabular}{llccc}
\hline & \multicolumn{2}{l}{ Mean (SD) } & & \\
\cline { 2 - 5 } & $n$ & Before fracture & One year following hospitalization & Change from baseline $^{\mathrm{a}}$ \\
\hline Barthel index & 50 & $92.5(15.1)$ & $91.7(16.2)$ & $-0.8(11.7)$ \\
EQ-5D & 50 & $0.772(0.235)$ & $0.807(0.166)$ & $0.035(0.254)$ \\
EQ-VAS & $49^{\mathrm{b}}$ & $62.6(21.7)$ & $79.6(16.8)$ & $17.0(22.0)$ \\
\hline
\end{tabular}

${ }^{\text {a }}$ Change from baseline was computed as the score at 1 year following hospitalization minus score prior to fracture.

${ }^{\mathrm{b}}$ One patient could not answer the EQ-VAS.

normal cognitive function, ADL recovery (as measured by Barthel index), and living without household help had positive influences on changes in EQ-VAS. Associated factors differed between the two QOL outcomes, suggesting that they may assess different aspects of QOL. One previous study of Japanese patients noted a significant correlation between EQ-5D and EQ-VAS, but a relatively low correlation coefficient $(r=0.46, p<0.01)$ [38]. The two measurements in our study had an even lower correlation coefficient $(r=0.29, p<0.05)$.

A positive correlation between age and change in QOL may imply a stronger response shift among older patients. Older individuals have decreased functional capacity and reduced expectations for self-performance, on average, than younger individuals. A previous study examined differences between 'self-reported' and 'observed' functionality and found that 'self-reported' function gradually increased,

Table 3 Factors associated with change in EQ-5D (multiple linear regression $\operatorname{model}^{\mathrm{a}}$ )

\begin{tabular}{|c|c|c|}
\hline & $B$ & $p$ \\
\hline Age (years) & 0.01 & 0.01 \\
\hline $\operatorname{Sex}^{\mathrm{b}}$ & -0.13 & 0.17 \\
\hline Fracture type ${ }^{\mathrm{c}}$ & -0.21 & 0.03 \\
\hline Operation type $^{\mathrm{d}}$ & 0.03 & 0.62 \\
\hline Length of hospital stay (days) & 0.00 & 0.81 \\
\hline Cognitive function ${ }^{\mathrm{e}}$ & -0.04 & 0.65 \\
\hline Number of comorbidities & -0.01 & 0.65 \\
\hline Residence type 1 year following hospitalization ${ }^{f}$ & -0.25 & 0.04 \\
\hline $\begin{array}{l}\text { Household help required } 1 \text { year following } \\
\text { hospitalization }^{\mathrm{g}}\end{array}$ & 0.09 & 0.25 \\
\hline
\end{tabular}

${ }^{a}$ The dependent variable was given by the change from baseline (score at 1 year after hospitalization-score before fracture). The $R$ square value was $0.16, p=0.06$.

${ }^{\mathrm{b}}$ Sex: male $=1$, female $=2$.

${ }^{\mathrm{c}}$ Fracture type: femoral neck fracture $=1$, trochanteric fracture $=2$.

${ }^{\mathrm{d}}$ Operation type: hemiarthoplasty $=1$, compression hip screw or gamma nail $=2$, multiple pinning $=3$.

${ }^{\mathrm{e}}$ Cognitive function: normal $=1$, moderate cognitive decline $=2$.

${ }^{\mathrm{f}}$ Residence type at 1 year following hospitalization: own home $=1$, other $=2$.

${ }^{\mathrm{g}}$ Household help required 1 year after hospitalization: yes=1, no=2. while 'observed' function decreased with age [39]. In other words, younger individuals expect to function at a higher level and thus are more likely than older individuals to report a higher level of disability.

Controlling for age, mental and physical factors were significantly associated with changes in QOL in our study. Hip fracture patients with impaired cognitive function have an increased risk of complications, poor long-term outcomes and an increased mortality rate [40]. When examining QOL, individuals with severe cognitive dysfunction are often excluded, as in our study. As such, only a few studies among this population have been conducted. One prospective clinical study in Sweden found that hip fracture patients with severe cognitive dysfunction showed a continuous deterioration in EQ-5D score compared with patients who did not have severe cognitive dysfunction [40]. These findings probably reflect the natural course of

Table 4 Factors associated with change in EQ-VAS (multiple linear regression model $^{\text {a) }}$ )

\begin{tabular}{|c|c|c|}
\hline & $B$ & $p$ \\
\hline Age (year) & 0.49 & 0.16 \\
\hline $\mathrm{Sex}^{\mathrm{b}}$ & -11.45 & 0.13 \\
\hline Fracture type $\mathrm{c}^{\mathrm{c}}$ & -3.91 & 0.59 \\
\hline Operation type ${ }^{\mathrm{d}}$ & 3.94 & 0.43 \\
\hline Length of hospital stay (day) & 0.44 & 0.28 \\
\hline Cognitive function ${ }^{\mathrm{e}}$ & -14.40 & 0.04 \\
\hline Number of comorbidities & -2.92 & 0.23 \\
\hline Residence type 1 year following hospitalization ${ }^{f}$ & -6.19 & 0.54 \\
\hline $\begin{array}{l}\text { Household help required } 1 \text { year following } \\
\text { hospitalization }^{\mathrm{g}}\end{array}$ & 19.18 & 0.01 \\
\hline Change in Barthel index & 0.73 & 0.01 \\
\hline
\end{tabular}

${ }^{\mathrm{a}}$ The dependent variable was given by the change from baseline. The $R$-square value was $0.16, p=0.06$.

${ }^{\mathrm{b}}$ Sex: male $=1$, female $=2$.

${ }^{\mathrm{c}}$ Fracture type: femoral neck fracture $=1$, trochanteric fracture $=2$.

d Operation type: hemiarthoplasty $=1$, compression hip screw or gamma nail $=2$, multiple pinning $=3$.

${ }^{\mathrm{e}}$ Cognitive function: normal $=1$, moderate cognitive decline $=2$.

${ }^{\mathrm{f}}$ Residence type 1 year following hospitalization: own home $=1$, other $=2$.

${ }^{\mathrm{g}}$ Household help required 1 year after hospitalization: yes=1, no=2. 
cognitive impairment, the difficulty for these patients to follow rehabilitation regimens and to adjust to physical and functional changes, and inadequate rehabilitation resources for this specific group. Regarding ADL, the same research team from Sweden later reported that patients with a high level of functional independence had significantly higher EQ-5D scores than those who were more dependent at both 4 months and 17 months after hip fracture [41]. The significant association between ADL and QOL in our subjects (who exhibited favorable postoperative functional recovery) suggests that there is a strong influence of ADL on QOL.

With regards to fracture type, a previous study comparing trochanteric and femoral neck fractures reported that patients with the former were characterized by poorer health and consequent delayed recovery [42]. Our findings agree with these in that changes in QOL were greatest in patients with femoral neck fractures. However, the results obtained regarding fracture type and cognitive decline should be interpreted with caution because of the significant differences between patients who were and were not included in the overall analyses. The proportion of patients with trochanteric fracture and moderate cognitive decline was significantly higher in the group of patients who were excluded from overall analyses. As such, even stronger associations may have been masked.

It is noteworthy that living arrangements (including residence type and household help) at the time of follow-up were associated with changes in QOL. We found that patients who lived at home and/or without household help had more positive changes in QOL. It should be noted that the cause-effect relationships are unclear due to the crosssectional nature of these survey items, and that the results do not necessarily mean, for example, that having household help negatively influences QOL. In other words, it is likely that the recovery of individuals who maintained high QOL was such that daily assistance was not required and living at home was possible. In either case, these results emphasize the importance of assessing and being aware of patients' living conditions [43].

This study had three methodological limitations. Firstly, the survey took place at a single private hospital and the total number of registered subjects was small $(N=113)$. Data from only 50 follow-up respondents $(62 \%)$ were included in our analyses after excluding for severe cognitive decline. Since respondents of epidemiological surveys tend to be healthier, the high attrition rate might have led to an underestimation of decline in QOL and its association with surveyed factors. The 1-year follow-up rate, however, was comparable to previous studies (50$80 \%$ ) [21, 41]. For future research, a multi-center study with a larger sample size is warranted. Secondly, a large proportion $(27 \%)$ of patients with severe cognitive decline was excluded from analyses because of difficulties in completing QOL questions and less reliable answers. A previous study that included patients with severe cognitive decline suffered from a low response rate. Only $51 \%$ of patients were able to complete the SF-36 questionnaire and respondents were considerably younger, had less cognitive impairment and had better functional status than nonrespondents [21]. Similarly, only three of the 31 patients with severe cognitive decline were able to answer the QOL questions in our study. Although our findings can only be generalized to hip fracture patients without severe cognitive dysfunction, this does not alter the internal validity of the results regarding factors associated with changes in QOL. Thirdly, a recall bias of baseline QOL and ADL levels could not be avoided because we used "pre-injury recall" as previously noted. Since patients' recall may not be accurate, we repeated the same multivariate analyses using QOL and ADL scores at the time of discharge as the baseline data and found that no factor remained significant related to either EQ-5D or EQ-VAS.

In conclusion, we found that there was less of a decline in Euro-QOL after hip fracture in our cohort of Japanese patients. Changes in Euro-QOL, however, varied between patients, and were associated with age, cognitive function, ADL, fracture type, residence type, and household help. These findings suggest that to maintain and improve QOL in Japanese hip fracture patients, closer attention should be paid to patient age, cognitive status, and fracture type. They also highlight the importance of providing social support in addition to medical care to these patients.

Acknowledgments The authors wish to thank Dr. Yasufumi Sekiguchi (director of the Orthopaedic Department at Ohara General Hospital) and Dr. Hiroyuki Anzai (director of the Anzai Orthopaedic Clinic) for their assistance in data collection.

\section{Conflicts of interest None.}

Open Access This article is distributed under the terms of the Creative Commons Attribution Noncommercial License which permits any noncommercial use, distribution, and reproduction in any medium, provided the original author(s) and source are credited.

\section{References}

1. Lips P, van Schoor NM (2005) Quality of life in patients with osteoporosis. Osteoporos Int 16:447-455

2. Hagino H, Katagiri H, Okita $\mathrm{T}$ et al (2005) Increasing incidence of hip fracture in Tottori Prefecture, Japan: Trend from 1986 to 2001. Osteoporos Int 16:1963-1968

3. Hagino H, Yamamoto K, Ohshiro H et al (1999) Changing incidence of hip, distal radius, and proximal humerus fractures in Tottori Prefecture, Japan. Bone 24:265-270

4. Yoshimura N, Suzuki T, Hosoi T et al (2005) Epidemiology of hip fracture in Japan: incidence and risk factors. J Bone Miner Metab $23: 78-80$ 
5. Committee for Osteoporosis Treatment of The Japanese Orthopaedic Association (2004) Nationwide survey of hip fractures in Japan. J Orthop Sci 9:1-5

6. Koh LK, Saw SM, Lee JJ et al (2001) Hip fracture incidence rates in Singapore 1991-1998. Osteoporos Int 12:311-318

7. Rowe SM, Song EK, Kim JS et al (2005) Rising incidence of hip fracture in Gwangju City and Chonnam Province, Korea. J Korean Med Sci 20:655-658

8. Roder F, Schwab M, Aleker T et al (2003) Proximal femur fracture in older patients - rehabilitation and clinical outcome. Age Ageing 32:74-80

9. Nevalainen TH, Hiltunen LA, Jalovaara P (2004) Functional ability after hip fracture among patients home-dwelling at the time of fracture. Cent Eur J Public Health 12:211-216

10. Tsauo JY, Leu WS, Chen YT et al (2005) Effects on function and quality of life of postoperative home-based physical therapy for patients with hip fracture. Arch Phys Med Rehabil 86:1953-1957

11. Fierens J, Broos PL (2006) Quality of life after hip fracture surgery in the elderly. Acta Chir Belg 106:393-396

12. Sakamoto K, Nakamura T, Hagino H et al (2006) Report on the Japanese Orthopaedic Association's 3-year project observing hip fractures at fixed-point hospitals. J Orthop Sci 11:127-134

13. Takeda H, Kamogawa J, Sakayama K et al (2006) Evaluation of clinical prognosis and activities of daily living using functional independence measure in patients with hip fractures. J Orthop Sci 11:584-591

14. Vatansever A, Ozic U, Okcu G (2005) Assessment of quality of life of patients after hemiarthroplasty for proximal femoral fractures. Acta Orthop Traumatol Turc 39:237-242

15. Beloosesky Y, Grinblat J, Epelboym B et al (2002) Functional gain of hip fracture patients in different cognitive and functional groups. Clin Rehabil 16:321-328

16. Soderqvist A, Miedel R, Ponzer S et al (2006) The influence of cognitive function on outcome after a hip fracture. J Bone Jt Surg Am 88:2115-2123

17. Hall SE, Williams JA, Senior JA et al (2000) Hip fracture outcomes: quality of life and functional status in older adults living in the community. Aust N Z J Med 30:327-332

18. Randell AG, Nguyen TV, Bhalerao N et al (2000) Deterioration in quality of life following hip fracture: a prospective study. Osteoporos Int 11:460-466

19. Van Balen R, Essink-Bot ML, Steyerberg E et al (2003) Quality of life after hip fracture: a comparison of four health status measures in 208 patients. Disabil Rehabil 25:507-519

20. Tidermark J (2003) Quality of life and femoral neck fractures. Acta Orthop Scand Suppl 74:1-42

21. Boonen S, Autier P, Barette M et al (2004) Functional outcome and quality of life following hip fracture in elderly women: a prospective controlled study. Osteoporos Int 15:87-94

22. Blomfeldt R, Tornkvist H, Ponzer S et al (2005) Comparison of internal fixation with total hip replacement for displaced femoral neck fractures. Randomized, controlled trial performed at four years. J Bone Jt Surg Am 87:1680-1688

23. Keating JF, Grant A, Masson M et al (2006) Randomized comparison of reduction and fixation, bipolar hemiarthroplasty, and total hip arthroplasty. Treatment of displaced intracapsular hip fractures in healthy older patients. J Bone Jt Surg Am 88:249-260
24. Shyu YI, Chen MC, Liang J et al (2004) Changes in quality of life among elderly patients with hip fracture in Taiwan. Osteoporos Int 15:95-102

25. EuroQol Group. EuroQol (1990) A new facility for the measurement of health-related quality of life. Health Policy 16:199-208

26. Brooks RG (1996) EuroQol: the current state of play. Health Policy 37:53-72

27. Rabin R, de Charro F (2001) EQ-5D: a measure of health status from the EuroQol Group. Ann Med 33:337-343

28. Haywood KL, Garratt AM, Fitzpatrick R (2005) Quality of life in older people: a structured review of generic self-assessed health instruments. Qual Life Res 14:1651-1668

29. Coast J, Peters TJ, Richards SH et al (1998) Use of the EuroQoL among elderly acute care patients. Qual Life Res 7:1-10

30. Ryan T, Enderby P, Rigby AS (2006) A randomized controlled trial to evaluate intensity of community-based rehabilitation provision following stroke or hip fracture in old age. Clin Rehabil 20:123-131

31. Tidermark J, Bergström G, Svensson O et al (2003) Responsiveness of the EuroQol (EQ 5-D) and the SF-36 in elderly patients with displaced femoral neck fractures. Qual Life Res 12:1069-1079

32. Tidermark J, Bergström G (2007) Responsiveness of the EuroQol (EQ-5D) and the Nottingham Health Profile (NHP) in elderly patients with femoral neck fractures. Qual Life Res 16:321-323

33. Mahoney FI, Barthel DW (1965) Functional evaluation: the Barthel index. Md State Med J 14:61-65

34. Folstein MF, Folstein SE, McHugh PR (1975) Mini-mental state. A practical method for grading the cognitive state of patients for the clinician. J Psychiatr Res 12:189-198

35. Fu AZ, Kattan MW (2006) Racial and ethnic differences in preference-based health status measure. Curr Med Res Opin 22:2439-2448

36. Albrecht GL, Devlieger PJ (1999) The disability paradox: high quality of life against all odds. Soc Sci Med 48:977-988

37. Schwartz CE, Andresen EM, Nosek MA et al (2007) Response shift theory: important implications for measuring quality of life in people with disability. Arch Phys Med Rehabil 88:529-536

38. Fujita M, Hayashi K, Ozaka K et al (2001) QOL survey among basic health check up participant. Journal of Health and Welfare Statistics 48:22-27 (in Japanese)

39. Daltroy LH, Larson MG, Eaton HM et al (1999) Discrepancies between self-reported and observed physical function in the elderly: the influence of response shift and other factors. Soc Sci Med 48:1549-1561

40. Soderqvist A, Miedel R, Ponzer S et al (2006) The influence of cognitive function on outcome after a hip fracture. J Bone Jt Surg Am 88:2115-2123

41. Tidermark J, Zethraeus N, Svensson O et al (2002) Femoral neck fractures in the elderly: functional outcome and quality of life according to EuroQol. Qual Life Res 11:473-481

42. Fox KM, Magaziner J, Hebel JR et al (1999) Intertrochanteric versus femoral neck hip fractures: differential characteristics, treatment, and sequelae. J Gerontol A Biol Sci Med Sci 54: M635-M640

43. Osnes EK, Lofthus CM, Meyer HE et al (2004) Consequences of hip fracture on activities of daily life and residential needs. Osteoporos Int 15:567-574 